\title{
Examine Counting Procedure among Students with Mild Intellectual Disability: A Case of Penang Malaysia
}

\author{
Adiat B. Taibat ${ }^{1}$, Aznan Che Ahmad ${ }^{1} \&$ Munirah Ghazali $^{1}$ \\ ${ }^{1}$ School of educational studies, Universiti Sains Malaysia, Malaysia \\ Correspondence author: Taibat Bolanle Adiat, School of educational studies, Universiti Sains Malaysia, \\ Malaysia. Tel: 60-147-565-673. E-mail: adiattaibat@yahoo.co.uk
}

\author{
Received: January 16, 2013 Accepted: January 21, 2013 Online Published: April 26, 2013 \\ doi:10.5539/ies.v6n5p33 \\ URL: http://dx.doi.org/10.5539/ies.v6n5p33
}

This manusript was funding by universiti sains malaysia.

\begin{abstract}
This study investigates counting procedure in number counting based on gender among students with mild intellectual disability. Quantitative approach was used for testing counting procedure in number counting among these students. The samples for the study comprise fifteen male and fifteen female students with intellectual disability. Descriptive statistics and T-test were used in analyzing the data. It was revealed from the result of the study that students with mild intellectual disability showed understanding of counting procedure in number counting. However, the results of the study showed that these students have difficulty in number counting using abstraction principle and order irrelevance principle. It was shown that there was no significant difference between males and females in number counting when applying counting procedure.
\end{abstract}

Keywords: number counting, gender, counting procedure, students with mild intellectual disability

\section{Introduction}

The awareness of establishing a good foundation in developing number counting among students with disability has been increased. This is because of its various significances to many aspects of life (Valerie, 2009). Number counting is proven to be a way of developing one's understanding of number through learning about different ways of representing numbers and the relationship among numbers as well as developing a sense of magnitude (Ministry of Education Ontario, 2005). Patton et al. (1996) had identified primary goals that students with mild intellectual disability need to achieve in life are successful employment, independent living, competence in basic life skills, and successful integration into schools and community settings. Therefore, developing appropriate instructions for students with mild intellectual disability is important when considering the postsecondary transition to adulthood (Frances, 2001). In achieving these goals, the importance of examining counting procedure in number counting cannot be overemphasized. This is because learning numbers counting through the use of counting procedures are significant to so many aspect of life. However, Cawley, et al. (2001) found that students with disability fail to demonstrate grade-level proficiency in solving counting procedural task. Students with disability have persistent deficits in some areas of number counting skills when applying counting procedure. Many of these students have immatured understanding of certain counting procedure which makes them frequently commit errors (Geary \& Hoard, 2005).

Learning number counting using counting procedure can be achieved through the use of objects as a result of this, National Council of Teachers of Mathematics (NCTM) (2000) found that learning number counting with visual images include number frames, sticks and later, base-ten materials would allow these students to move from concrete materials to visual representations as each counting procedure is introduced. However, Hendler and Weisberg (1992) have recognized that students with disability often have difficulty with symbolic representation of quantity on counting procedural task. NCTM (2000) further established that the development of each counting procedure follows a proven sequence of stages: introduce; reinforce; and practice. During the introduction stage, pictorial materials are to be used to move students with mild intellectual disability away from counting individual objects to add or subtract. The reinforcement stage connects the picture to the appropriate number sentence and encourages students to use each counting procedure with visual aid. However, Research is lacking 
in area of counting procedure on number counting that directly involve students with mild intellectual disability based on gender. Therefore, this study aims at investigating counting procedure in number counting based on gender among students with mild intellectual disability.

\section{Theoretical Background}

\subsection{Number Counting}

Acquisition of mathematical abilities among students with mild intellectual disability begins physically, mentally and by counting hand, depends on the experiences that such child gains during his interaction with the environment (Chao et al., 2000; Frakes \& Kline, 2000; Geist, 2001). Temple and Sherwood (2002) found that the use of counting procedures by students appear to result in the development of memory representations of basic facts. Developing an understanding of the meanings of the whole numbers and recognizing the number of objects in small groups without counting or by counting to ten and beyond is the first and most basic mathematical algorithm (NCTM, 2006).

Besides, learning number countings serve as keys to construct initial number concepts among students with disability (Baroody et al.,2003; Benson \& Baroody, 2002; Mix et al., 2005; Sandhofer \& Mix, 2003; Spelke, 2003a, 2003b; Van deWalle et al., 2000). Furthermore, counting is a critical component in learning mathematics and it is also a key basis for extending number understanding beyond the small numbers (Baroody et al., 2006). Van de Walle (2003) pointed out that counting tells how many things are in a set. When counting a set of objects, the last word in the counting sequence names the quantity for that set.

\subsection{Counting Procedures}

The hierarchical principles of counting developed by Gelman and Gallistel in (1978) cited in the work of Geary and Hoard (2005) are the counting procedures that are to be examining in number counting among students with mild intellectual disability. The hierarchical principles are one-one principle, stable order principle, cardinality principle, abstraction principle, and order-irrelevance principle. One -one principle implies that one and only one word is tagged or assigned to each counted object; Stable order principle implies that the order of the word tags must be invariant across counted sets; Cardinality principle implies that the value of the final word tag represents the quantity of items in the counted set; Abstraction principle implies that objects of any kind can be collected together and counted; and Order-irrelevance principle implies that items within a given set can be tagged in any sequence).

In another development, developing number counting using counting procedure would enable students with learning disability particularly students with mild intellectual disability to survive and live independent life in future. Le Fevre et al. (2006) suggested that students with disability did not understand some of the counting procedural task. He maintained further that these students may make errors in their counting procedural tasks due to lack of monitoring problems. Gelman and Gallistel (1978) see Treacy (2001) observed that students with disability have innate understanding of counting procedure. Le Corre et al. (2006) confirmed that students with disability have developed verbal counting procedural knowledge before the development of conceptual knowledge. They maintained further that these students had higher average levels on one on one correspondence principle than females. Sarnecka and Lee (2009) maintained that children with disability may appear as if they have mastered counting of numbers because they seem confident in reciting the counting sequence and repeating the last number word used in the count to answer the question "how many", but what this appearance might reflect is just an observational learning (Clements \& Sarama, 2009).

Bermejo, 1996; see Sadler and Faith (2009) confirmed that some young children had master cardinality principle; they go through phases of subset knowing. This might be due to less counting experience these children have due to their deficiency. Furthermore, Sarnecka and Carey (2008) observed that children are likely to be more proficient in recognizing the cardinality principle which is understood when they start using counting procedure to make sets.

Gelman (1993) cited by Le Corre et al. (2006) noted that students with disability may do not better if cardinal value is explicitly mentioned. Freeman et al. (2000) claimed that children generally could simply have the same performance on the cardinality principle. Butterworth (2007) found that some of these students might not reach mastery of the three essential features at the same time. Knowledge of the stable-order principle is reliable first of all, followed by the one-one-correspondence principle, while mastery of the cardinality principle was found to develop as the slowest. Le Fevre et al. (2006) found that knowledge of this principle was very good for these types of students. They observed further that students with disability even reached an accuracy level than other students in understanding one-one-correspondence principle. 
Similarly, it was evident that children had higher average levels of achievement in answering with the largest number-tag included in the count but it may not have been the last tag used by these students (Slusser and Sarnecka, 2007). Clements and Sarama (2009) noted that children generally respond to the questions by completely recounting the set usually demonstrating one to one correspondence. He further observed that students with disability provide answers with the last number-tag used inaccurately. These children are not matured enough to monitor their counting to ensure its accuracy. Condry and Spelke (2008) noted that students with disability have poor number words fluency compare to normal students (abstraction). Bermejo et al. (2004) stated that children may simply count all five blocks instead of stopping at three, such not- stop" errors may be due to the fact that they do not remember the requested number or fail to monitor the counting-out process. Bermejo et al. (2004) also observed that children may realized that remembering number count is important but may not realized the objects-counting process that can be summarized before stating the last number word used (cardinality principle). In fact, it has been found that these students demonstrate a poor understanding of some counting principles (Geary, et al., 2000) and/or poor or faulty conceptual knowledge (Baroody, 2003). He maintained further that children generally did not understand the concepts of one on one labelling but may have difficulty in using it with sets of more than five items.

Clements and Sarama (2009) maintained that students with disability do not understand the question how many, and so they provide random answers. It's likely; however, that these students can provide answer correctly when shown very small quantities (1-3). They are recognizing them simply on sight and are using the terms "one," "two," and "three" as simply descriptive labels similar to colour words (Benson \& Baroody, 2002). Geary et al. (2000) noted that students with disability consistently made errors on tasks that assess abstraction principle than order-irrelevance. The use of counting procedures errors appears to result in the development of memory representations of basic facts for students with disability (Temple \& Sherwood, 2002).

Within the scope of literature reviewed in this study, it is observed that research had not been carried out on the use of these principles to examine the ability of students with or without disability in number counting. Furthermore, research so far lacked of gender base analysis of the differences on number counting using counting procedure.

\section{Research Questions}

The following research questions were investigated in this study:

(i) What are the skills of counting procedure do students with mild intellectual disability have?

(ii) What are the aspects of counting procedure do students with mild intellectual disability have difficulty in their skills?

(iii) Is there a significant difference in the counting procedure among students with mild intellectual disability according to their gender?

\section{Hypothesis}

The hypothesis below was postulated:

$\mathrm{H}_{0}$ : There is no significant difference in the counting procedure among students with mild intellectual disability according to gender

\section{Methodology}

The study adopts a pure quantitative approach. The sample comprised fifteen male and fifteen female students with mild intellectual disability in Penang Malaysia. The respondents were selected using simple random sampling technique.

\subsection{Instrument}

The instrument used for this study was numeracy assessment test adopted from Early Numeracy Interview Booklet (2001).The numeracy assessment test was designed for the abled students. It was however observed that the assessment test might be difficult for the children with mild intellectual disability to solve hence; aspect of number counting was adopted and modified to suit this study. The questions consisted of fifteen items and two rated scales of $(\sqrt{ })$ and $(\times)$ format. Furthermore, the test was conducted to students with mild intellectual disability in a structured way because these students were directed, assisted and motivated before they could produce answer to each item of these questions. On each of the test items in the number counting test using counting procedure, a score of one was given for a correct answer while a zero score was awarded for a wrong answer. However, the performances of these students were graded according to Graduate Admissions Fact Sheet United Kingdom (2006) which provide the following grade points 70 and above serves excellent, 60-69 stand for 
very good, 50-59 stand for good, 45-49 stand for fair, 40-44 serves pass and below 40 serves as fail.

\subsection{Analysis of Data}

The data was analyzed by using both the descriptive statistics and the independent t-test techniques. The software utilized for the data analysis was the statistics package for social scientists (spss) version 18. In the descriptive statistics the percentage scores for number counting using counting procedural steps were estimated for all the respondents. This assisted in identifying the aspects of number counting that these students were strong and weak in term of performances. Furthermore, this also assisted in comparing the performances of the students according to gender. The test was carried out at 0.05 level of significance (i.e. alpha value of 0.05 ). The results of the t-test 1 form the basis for accepting the hypothesis of the study. Therefore, the result of the analysis of the study presented below.

\section{Results}

The following sections gave the detail findings of students' performances based on counting procedure on number counting. The findings on descriptive statistics in number counting test using counting procedures were discussed below;

Table 1. Scores of the Respondents in Number Counting from 1 to 10 Using One on One Principle

\begin{tabular}{ccc}
\hline Skills & \% Correct & Grades \\
\hline One - One principle1 & 80 & Excellent \\
One - One principle2 & 73.3 & Excellent \\
One - One principle3 & 76.7 & Excellent \\
One - One principle4 & 76.7 & Excellent \\
One - One principle5 & 66.7 & Very good \\
One - One principle6 & 60 & Very good \\
One - One principle 7 & 70 & Excellent \\
One - One principle 8 & 66.7 & Very good \\
One - One principle 9 & 63.3 & Very good \\
One - One principle 10 & 66.7 & Very good \\
Average & $70.01 \%$ & Excellent \\
\hline
\end{tabular}

Scores on one on one principle 1 had $(80 \%)$ followed by one on one principle $3 \& 4(76.7 \%)$, one on one principle $2(73.3 \%)$, one on one principle $7(70 \%)$ obtained excellent grades, while, one on one principle $5,8 \&$ 10 had $(66.7 \%)$, one on one principle 9 had $(63.3 \%)$, and one on principle 6 had $(60 \%)$ obtained very good. Hence overall average percentage on one on one principle had $(70.01 \%)$ which showed that these students had excellent mastering of one on one principle. 


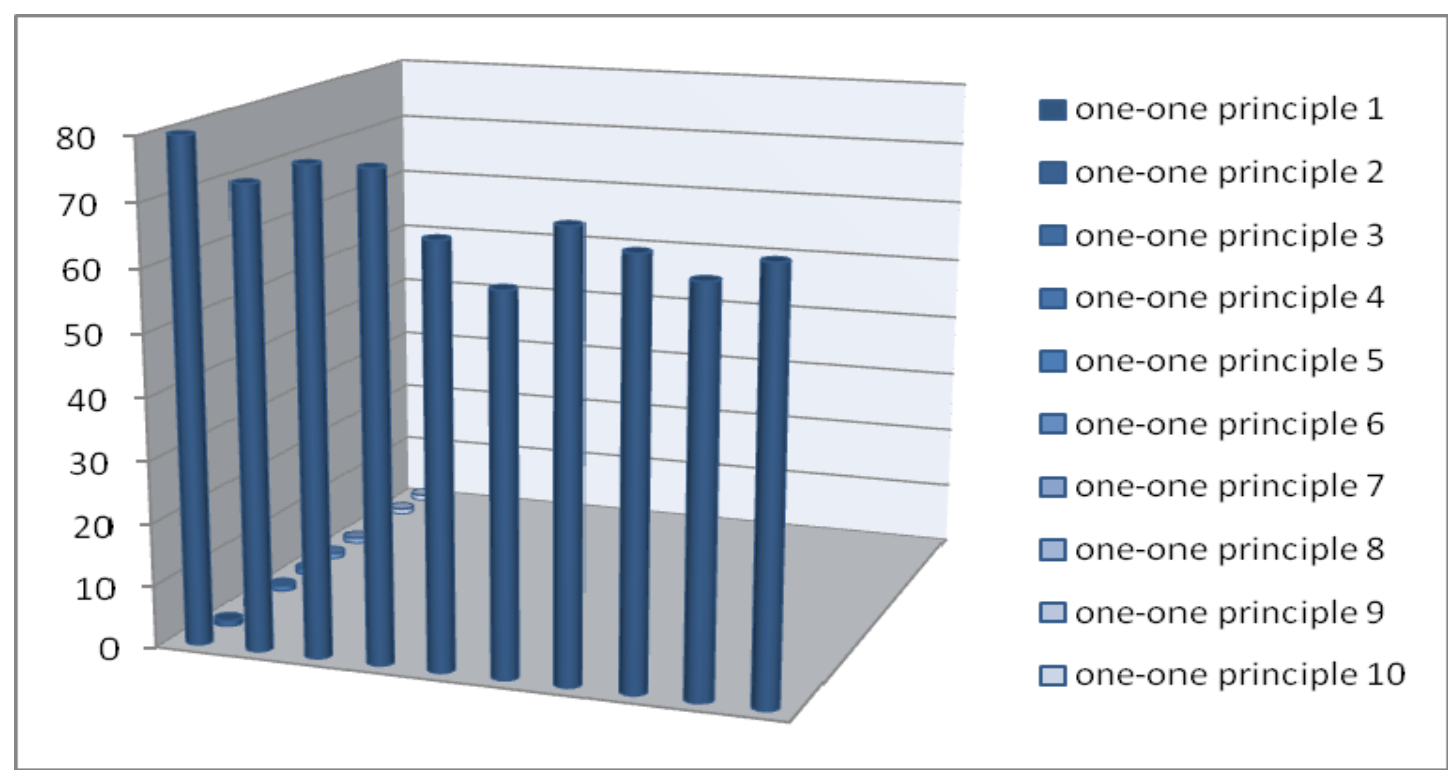

Figure 1. Percentage of Corrects on One on One Principle from Number Counting 1 to 10

The table below showed the correct percentage scores of the students in number counting $3,4,5$, and 6 using stable order principles.

Table 2. Scores of the Respondents in Number Counting from 3 to 6 Using Stable Order Principle

\begin{tabular}{ccc}
\hline Skills & \% Corrects & Grades \\
\hline Stable order 3 & 70 & Excellent \\
Stable order 4 & 76.7 & Excellent \\
Stable order 5 & 63.3 & Very good \\
Stable order 6 & 60 & Very good \\
Average & $67.50 \%$ & Very good \\
\hline
\end{tabular}

Stable order principle 4 had (76.7\%), stable order principle 3 had (70\%) which indicated that they had excellent grades, stable order principle 5 had (63.3\%) and stable order principle 6 had $(60 \%)$. It showed that they obtained very good score. Therefore, average overall percentage on stable order principle was $(67.50 \%)$ which revealed that on stable order principle these students had very good score. Graph below showed percentage of corrects on stable order principle. 


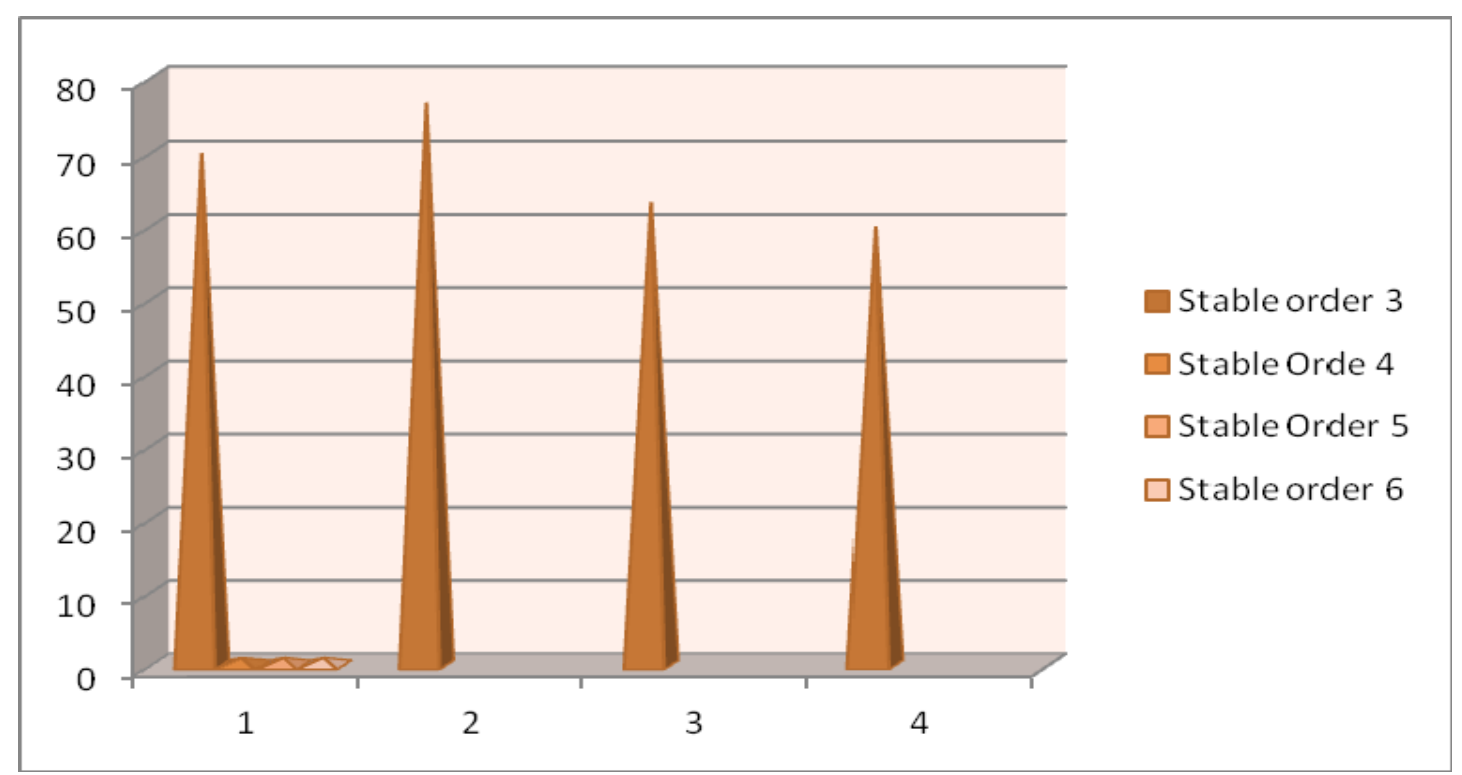

Figure 2. Percentage of Corrects on Stable Order Principle from Number Counting 3 to 6

The correct percentage scores of the respondents in counting numbers 3, 4, 5, 6 using cardinality principle showed in Table 3 .

Table 3. Scores of the Respondents in Number Counting from 3 to 6 Using Cardinality Principle

\begin{tabular}{ccc}
\hline Skills & \%Corrects & Grades \\
\hline Cardinality 3 & 60 & Very good \\
Cardinality 4 & 66.7 & Very good \\
Cardinality 5 & 73.3 & Excellent \\
Cardinality 6 & 70 & Excellent \\
Average & $67.50 \%$ & Very good \\
\hline
\end{tabular}

The correct scores on cardinality principle 5 had $(73.3 \%)$ followed by cardinality principle $6(70 \%)$ obtained excellent, while, cardinality principle 4 had (66.7\%), and cardinality principle 3 had (60\%) obtained very good. Therefore, overall average percentage score was $(67.50 \%)$ which showed that students with mild intellectual disability had very good score on cardinality principle. 


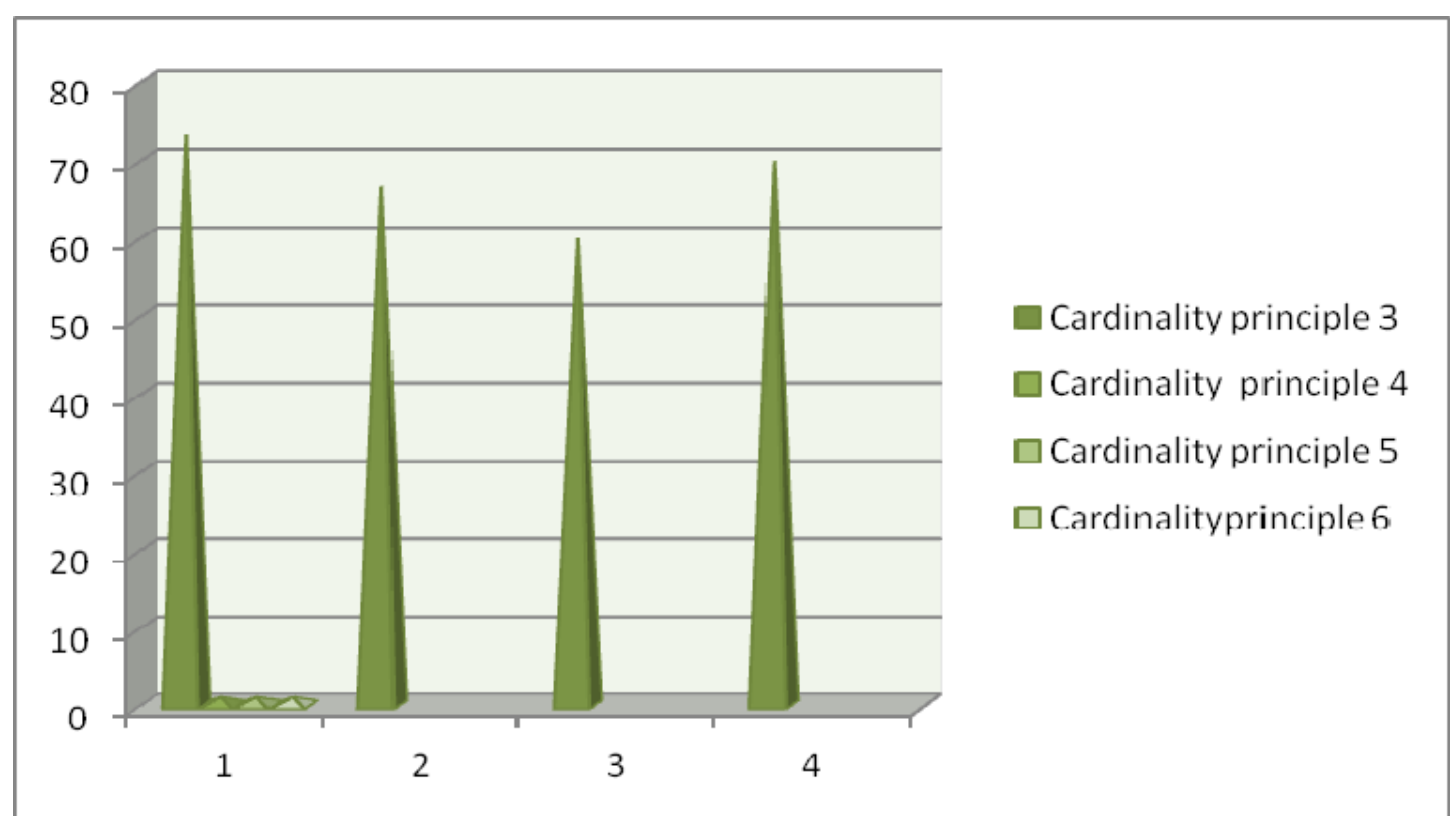

Figure 3. Percentage of Corrects on Cardinality Principle. from Number Counting 3 to 6

Table 4. Scores of the Respondents in Number Counting from 1 to 10 Using Abstraction Principle

\begin{tabular}{ccc}
\hline Skills & \%Correct & Scores \\
\hline Abstraction principle 1 & 43.3 & Pass \\
Abstraction principle 2 & 60 & pass \\
Abstraction principle 3 & 53.3 & Good \\
Abstraction principle 4 & 56.7 & Good \\
Abstraction principle 5 & 56.7 & Good \\
Abstraction principle 6 & 36.7 & Poor \\
Abstraction principle 7 & 60 & Very good \\
Abstraction principle 8 & 63.3 & Very good \\
Abstraction principle 9 & 46.6 & Pass \\
Abstraction principle 10 & 36.7 & Fail \\
Average & $51.33 \%$ & Good \\
\hline
\end{tabular}

The correct percentage scores of the respondents in counting numbers 1, 2, 3, 4, 5, 6, 7, 8, 9, 10 using abstraction principle presented in the above table. Scores on abstraction principle $8(63.3 \%)$ followed by abstraction principle $2 \& 7(60 \%)$ obtained very good grades followed by abstraction principle 5 \& $4(56.7 \%)$ and abstraction principle $3(53.3 \%)$ with good score, abstraction principle 9 had (46.6\%) and abstraction principle 1 had (43.3\%) obtained fair grades. While, abstraction principle $6 \& 10(36 \%)$ obtained fail grade. Hence overall average percentage on abstraction principle was $(51.33 \%)$ which showed that student scores fall within good grades. The graph on percentage correct scores on abstraction principle was conceptualized below. 


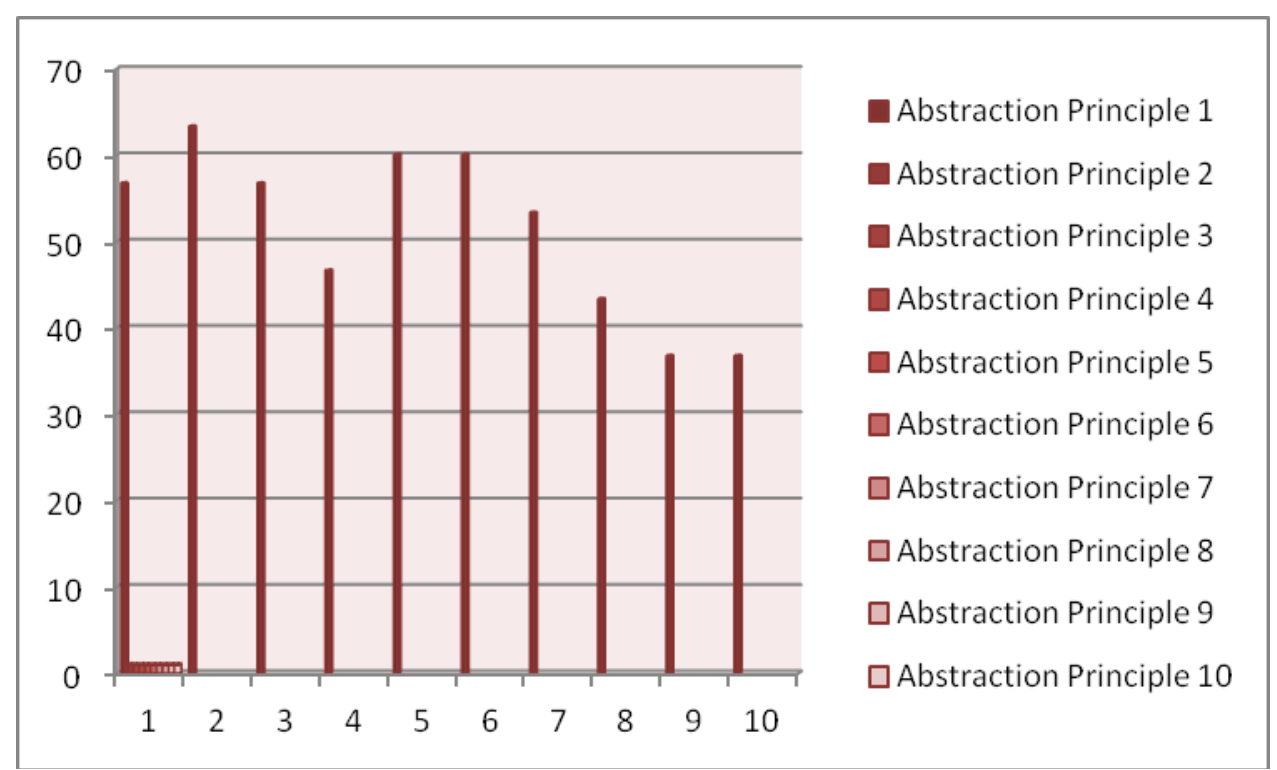

Figure 4. Percentage score of Corrects on Abstraction Principle from Number Counting 1 to 10

Table 5. Scores of the Respondents on Number Counting Using Order Irrelevance Principle

\begin{tabular}{lll}
\hline Skills & \%Correct & Grades \\
\hline Order irrelevance principle 2 & 56.7 & Good \\
Order irrelevance principle 4 & 56.7 & Good \\
Order irrelevance principle 5 & 53.3 & Good \\
Order irrelevance principle 8 & 50 & Good \\
Order irrelevance principle 10 & 53.3 & Good \\
Average & $54 \%$ & Good \\
\hline
\end{tabular}

The table above showed the correct percentage scores of the students with mild intellectual disability in counting numbers $2,4,5,8,10$, using order irrelevance principle. Grades on order irrelevance principle $2 \& 5$ was $(56.7 \%)$ followed by order irrelevance principle $5 \& 10$ had (53.3\%) and order irrelevance 8 had (50\%) obtained good grades. Overall average percentage correct using order irrelevance principle was (54\%) which showed that students with mild intellectual disability had good grades on order irrelevance principle. Therefore, percentage grades of corrects on order irrelevance were conceptualized on the graph below. 


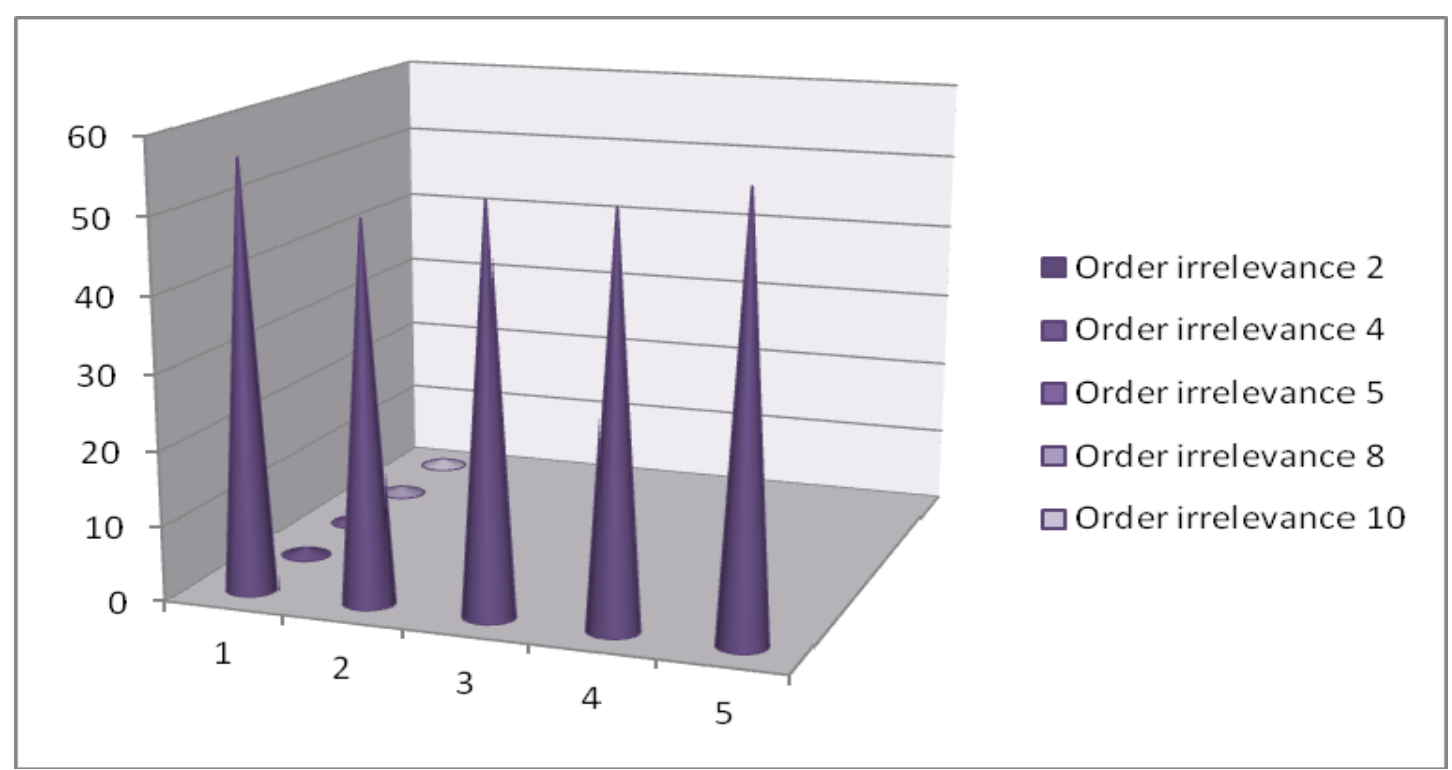

Figure 5. Percentage of corrects on Order Irrelevance Principl on Number Counting 2,4,5,8 and 10

\subsection{Descriptive Analysis for Comparism on Counting Procedure}

Table 6 showed overall average percentage correct and wrong for all the hierarchical principle in number counting.

Table 6. Comparism of average $\%$ corrects and wrongs on Hierarchical Principle

\begin{tabular}{cccc}
\hline Skills & \% Correct & \% Wrong & Grades \\
\hline & & & \\
One-One principle & $70.01 \%$ & $29.99 \%$ & Excellent \\
Stable order principle & $67.50 \%$ & $32.50 \%$ & Very good \\
Cardinality principle & $67.50 \%$ & $32.50 \%$ & Very good \\
Abstraction principle & $51.33 \%$ & $48.66 \%$ & Good \\
Order irrelevance principle & $54 \%$ & $46 \%$ & Good \\
\hline
\end{tabular}

The overall average percentage grades on corrects for one on one principle was $(70.01 \%)$, which indicated that one on one principle obtained excellent grade in all counting procedural steps, followed by stable order principle and cardinality principle had $(67.50 \%)$, order irrelevance principle have $(54 \%)$, abstraction principle have $(51.33 \%)$ which showed that these students obtained good grade. Therefore, overall average percentages correct and wrong were conceptualized below in a separate graph for comparism in order to know the aspects of the counting procedure that these students having problems in their skills. 


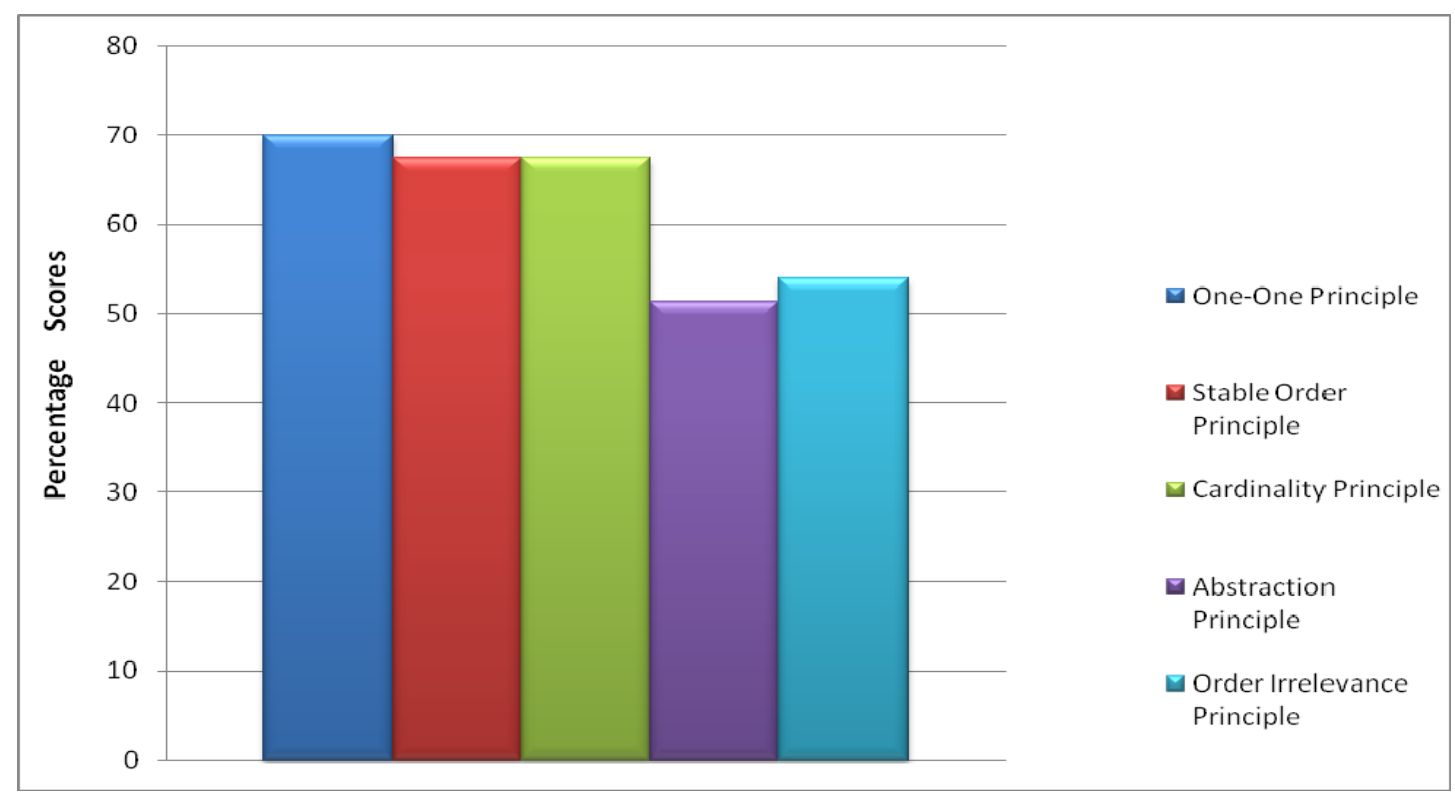

Figure 6. Comparism of Overall Average Percentage of Corrects on Hierarchical Principles

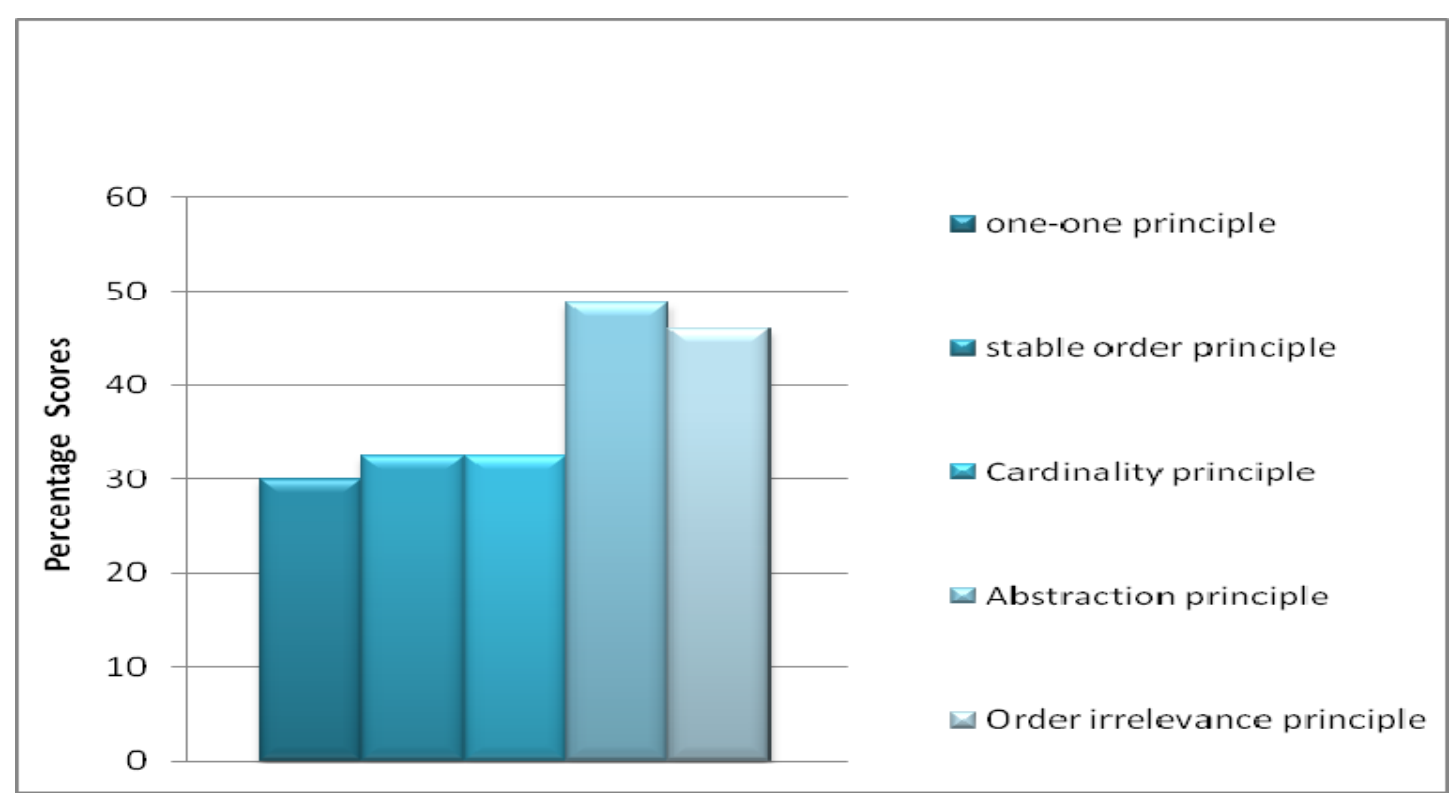

Figure 7. Comparism of Overall Average Percentage of Wrongs on Hierarchical Principles

\subsection{Comparison of Number Counting Using Counting Procedure according Gender}

Analysis was done to compare the differences in the number counting scores using counting procedure between genders by the respective skills, namely one on one principle, stable order principle, cardinality principle, abstraction principle and order irrelevance respectively. 
Table 7. Summarizes statistics results for the number counting using counting procedure based on gender across the skills

\begin{tabular}{ccccc}
\hline Skills & Gender & $\mathrm{N}$ & Mean & Std. Deviation \\
\hline One-one principle & Male & 16 & 6.6875 & 3.80734 \\
& Female & 14 & 7.3571 & 4.21731 \\
Stable order principle & Male & 16 & 2.5625 & 1.78769 \\
& Female & 14 & 2.8571 & 1.74784 \\
Cardinality principle & Male & 16 & 2.4375 & 1.86078 \\
& Female & 14 & 3.0000 & 1.70970 \\
Abstraction principle & Male & 16 & 5.1875 & 4.19871 \\
& Female & 14 & 5.0714 & 3.97036 \\
Order irrelevance principle & Male & 16 & 2.8125 & 2.45544 \\
& Female & 14 & 2.5714 & 2.40878 \\
\hline
\end{tabular}

It was shown from above that the mean scores on one on one principle; stable order principle and cardinality principle are higher for female students with mild intellectual disability as compared to that of male students with intellectual disability. While, the mean scores on abstraction principle and order irrelevance principle indicated that male students with mild intellectual disability have higher mean score compare to female students.

Table 8. Independent Samples t-test for counting procedure

\begin{tabular}{ccccc}
\hline \multicolumn{5}{c}{ t-test for equality of means between } \\
gender (male-female) & \multicolumn{5}{c}{} \\
\hline Skills & $\mathrm{t}$ & Sig.(2-tailed) & Mean Difference & Std. Error Difference \\
Counting procedure & -.244 & .809 & -1.16964 & 4.79115 \\
\hline
\end{tabular}

The mean difference is significant at the .05 level.

Above table showed an independent samples t-test of the study on counting procedure. The levene's test for equality of variance showed that $(\mathrm{p}=.730)$ which is greater than alpha value as a result of checking the equal variances assumed as $(\mathrm{t}=-.399$, sig. 2-tailed $=.693)$. The sig. 2 - tailed is greater than 0.05 . It was shown that there was no significant difference between male and female on counting procedure. Therefore, hypothesis of the study was accepted.

\section{Discussion}

The result reported in this study reveals a great development on learning number counting among students with mild intellectual disability. Firstly, the study indicates that these students performed extremely high on one- one principle, stable order, and cardinality. the percentage of correct responses from other counting procedural steps fall within average percentage ranged from $(51.33 \%)$ to $(57.98 \%)$ in (Table $4 \& 5)$. This showed that the higher the use of counting procedural steps the lower the scores. Therefore, the results of the study were discussed: previous study conducted by Le Fevre et al. (2006) reveals similar findings with this study indicating that students with disability reached an accuracy level in understanding one-one-correspondence principle.

From the finding of this study female students seemed to perform better than male counterpart in using cardinality principle. This result negates the statement that students with disability could simply have the same performance on the cardinality principle (Freeman et. al., 2000). This same result confirmed the study conducted by Sadler and Faith (2009) which observed that students generally master the cardinality principle which showed that they go through phases of subset knowing. The study also supports Sarnecka and Carey (2008) which noted that students with disability are likely to be more proficient in recognizing the cardinality principle when they start using number counting to make sets compare to other counterparts. However, result from this study showed that students with mild intellectual disability performed poor on abstraction principle which agreed with the 
finding of Condry and Spelke (2008) which confirmed that students with disability have poor number words fluency.

The result of this study indicated that the mean scores on one on one principle; stable order principle and cardinality principle were higher for female students with mild intellectual disability as compared to that of male students with intellectual disability. While, the mean scores on abstraction principle and order irrelevance principle indicated that male students with mild intellectual disability had higher mean score compare to female students.It was further revelead from the result ofthe study that there was no significant difference between male and female on counting procedure.

\section{Concluding Remarks}

In an effort to develop students with mild intellectual disability number counting ability in order to live independent lives rather than being dependent. This study suggests that counting procedures are to be adopted in teaching and learning of these students in all aspects of numeracy so that their learning can be facilitated. This can also serves as one of the ways through which their brains can be utilized in order to cope with the other challenges after schooling. The importance of number counting abilities using counting procedure in our education system has been emphasized by (Stock, et al., 2009). The study concluded that acquisition of number counting would develop the learning quality of students with disability particularly students with mild intellectual disability. This is because early mastery of the number counting is correlated with better arithmetic performance.

\section{References}

Baroody AJ, Lai ML, \& KS, M. (2006). The development of young children's early number and operation sense and its implications for early childhood education. In Spodek B., \& Saracho O. (Ed.), Handbook of research on the education of young children (pp. 187-221). Mahwah, NJ: Lawrence Erlbaum Associates.

Baroody, A. J., Benson, A. P., \& Lai, M. L. (2003). Early number and arithmetic sense: A summary of three studies. Paper presented at the Biennial meeting of the society for Research in Child Development, Tampa, FL, April.

Benson, A., \& Baroody, A. J. (2002). The case of Blake: Number-word and number development. Paper presented at the Annual Meeting of the American Educational Research Association, New Orleans, LA.

Bermejo, V. (1996). Cardinality development and counting. Developmental Psychology, 32, 263-268. http://dx.doi.org/10.1037/0012-1649.32.2.263

Bermejo, V., Morales, S., \& de Osuna, J. G. (2004). Supporting children's development of cardinality understanding. Learning and Instruction, 14, 381-398. http://dx.doi.org/10.1016/j.learninstruc.2004.06.010

Butterworth. B., \& Reigosa, V. (2007). Information processing deficits in dyscalculia. In Berch MMD (Ed.), Why is math so hard for some children (pp. 65-81). Baltimore MD: Paul H. Brookes.

Cawley, J., Parmar, R., Foley, T. E., Salmon, S., \& Roy, S. (2001). Arithmetic performance of students: Implications for standards and programming. Exceptional Children, 19, 124-142.

Chao, J. S., Stigler, W. J., \& Woodward, A. J. (2000). The effects of physical materials on kindergartners' learning of number concepts). Cognition and Instruction, 18(3), 285-316. http://dx.doi.org/10.1207/S1532690XCI1803_1

Clements, D., \& Sarama, J. (2009). Learning and teaching early math: The learning trajectories approach. New York, NY: Routledge of the Taylor \& Francis Group.

Condry, K. F., \& Spelke, E. S. (2008). The development of language and abstract concepts: The case of natural number. Journal of Experimental Psychology: General, 137, 22-38. http://dx.doi.org/10.1037/0096-3445.137.1.22

Early Numeracy Interview Booklet. (2001). Mathematics online interview; Published by the Communications Division, for the Office of School Education, Department of Education, Employment and Training, GPO Box 4367, Melbourne, Vic. 3001, Australia. (C) State of Victoria, August 2001. Retrieved February 15, 2011, from http://mathsonline.wordpress.com/2009/07/07/

Faith H. Sadler. (2009). Help! They Still Don't Understand Counting. TEACHING Exceptional Children Plus, $6(1)$.

Frakes, C., \& Kline, K. (2000). Teaching young mathematicians: The challenges and rewards. Teaching Children Mathematics, 6(6), 376-381. 
Frances M. Butler, Susan P. Miller, Lee, K. H., \& Pierce, T. (2001). Teaching Mathematics to Students with Mild-to-Moderate Mental Retardation: A Review of the Literature. Mental Retardation, 39(1), 20-31. http://dx.doi.org/10.1352/0047-6765(2001)039<0020:TMTSWM>2.0.CO;2

Freeman, N. H., Antonucci, C., \& Lewis, C. (2000). Representation of the cardinality principle: Early conception of error in a counterfactual test. Cognition, 74, 71-89. http://dx.doi.org/10.1016/S0010-0277(99)00064-5

Geary, D. C., \& Hoard, M. K. (2005). Learning disabilities in arithmetic and mathematics: Theoretical and empirical perspectives. In J. I. D. Campbell (Ed.), Handbook of mathematical cognition (pp. 253-267). New York: Psychology Press.

Geary, D. C., Hamson, C. O., \& Hoard, M. K. (2000). Numerical and arithmetical cognition: A longitudinal study of process and concept deficits in children with learning disability. Journal of Experimental Child Psychology, 77, 236-263. http://dx.doi.org/10.1006/jecp.2000.2561

Geist, E. (2001). Children are born mathematicians: Promoting the construction of early the mathematical concepts in children under five. Young Children, 56(4), 12-18.

Gelman, R., \& Gallistel, C. R. (1978). The child's understanding of number. Cambridge, MA: Harvard University Press.

Gelman, R. (1993). A rational-constructivist account of early learning about numbers and objects. In D. L. Medin (Ed.), The Psychology of Learning and Motivation. Advances in Research Theory, 30, 61-96. http://dx.doi.org/10.1016/S0079-7421(08)60294-7

Hendler, M., \& Weisberg, P. (1992). Conservation acquisition, maintenance, and generalization by mentally retarded children using equality- rule training. Journal of Experimental Child Psychology, 53, 258-276. http://dx.doi.org/10.1016/0022-0965(92)90039-9

Le Corre, M., Van de Walle, G., Brannon, E. M., \& Carey, S. (2006). Re-visiting the competence/performance debate in the acquisition of the counting principles. Cognitive Psychology, 52, 130-169. http://dx.doi.org/10.1016/j.cogpsych.2005.07.002

Le Fevre, J. A., Smith-Chant, B. L., Fast, L., Skwarchuk, S. L., Sargla, E., \& Arnup, J. S., et al. (2006). What counts as knowing? The development of conceptual and procedural knowledge of counting from kindergarten through Grade 2. Journal of Experimental Child Psychology, 93, 285-303. http://dx.doi.org/10.1016/j.jecp.2005.11.002

Ministry of Education Ontario. (2005). The Ontario Curriculum Grades 1-8 Mathematics.

Mix, K. S., Sandhofer, C. M., \& Baroody, A. J. (2005). Number words and number concepts: The interplay of verbal and nonverbal processes in early quantitative development. In R. Kail (Ed.), Advances in Child Development and Behavior (Vol. 33, pp. 305-346). New York: Academic Press.

National Council of Teachers of Mathematics. (2000). Principles and standards for school mathematics. Reston, VA: Author.

National Council of Teachers of Mathematics, I. (2006). Curriculum focal points for Pre-kindergarten through grade 8 mathematics. Reston.

Patton, J. R., Smith T. E. C., Clark, G. M., Polloway, E. A., Edgar, E., \& Lee, S. (1996). Individuals with mild mental retardation: Postsecondary outcomes and implications for educational policy. Education and Training in Mental Retardation and Developmental Disabilities, 31, 75-85.

Sarnecka. B. W., \& Carey. S. (2008). How counting represents number: what children must learn and when they learn it. Cognition, 108, 662-674. http://dx.doi.org/10.1016/j.cognition.2008.05.007

Slusser, E. B., \& Sarnecka, B. W. (2007, April). When do young children connect number words to discrete quantification? Poster presented at the biennial meeting of the Society for Research in Child Development, Boston, MA.

Spelke, E. S. (2003a, April). What makes humans smart? Invited address presented at the biennial meeting of the Society for Research in Child Development, Tampa, FL.

Spelke, E. S. (2003b). What makes us smart? Core knowledge and natural language. In D. Gente, \& S. Goldin-Meadow (Eds.), Language in mind. Cambridge, MA: MIT Press.

Temple, C. M., \& Sherwood, S. (2002). Representation and retrieval of arithmetical facts: Developmental difficulties. Quarterly Review of Experimental Psychology, 55A, 733-752. 
Treacy, K. (2001). Children's developing understanding of quantity and number as a representation of quantity. Unpublished Master's Thesis, Murdoch University, Perth, Western Australia.

United Kingdom. (2006). Graduate Admissions Fact Sheet : Minimum credentials required.

Valerie N. Faulkner (2009). The Components of Number Sense. An Instructional Modelfor Teachers. Teaching Exceptional Children, 41(5), 24-30. Copyright 2009 CEC.

Van de Rijt, B. A. M., R., Godfrey, C., Aubrey, J. E. H., Van Luit, P., Ghesquière, J., \& Torbeyns, K., et al. (2003). The development of early numeracy in Europe. Journal of Early Childhood Research, 1, 155-180. http://dx.doi.org/10.1177/1476718X030012002

Van de Walle. (2003). Elementary \& Middle School Mathematics Teaching Developmentally, 5/E: 0-205-38689-X Bookstore ISBN.

Van de Walle, J. A. (2001). Elementary and middle school mathematics. New York: Longman.

Van deWalle, G. A., Carey, S., \& Prevor, M. (2000). Bases for object individuation in infancy: Evidence from manual search. Journal of Cognition and Development, 1, 249-280. http://dx.doi.org/10.1207/S15327647JCD0103_1 